\title{
LOS POETAS-SOLDADOS Y EL TRASVASE CULTURAL EN EL RENACIMIENTO
}

\author{
Susana Guerrero Salazar \\ Universidad de Málaga. España.
}

El objetivo de estas páginas es reflexionar sobre la figura del soldadopoeta en el Renacimiento, pues no cabe duda de que personalidades literarias tan notables como Garcilaso, Acuña, Cetina, Figueroa o Aldana - quienes intervinieron activamente en la política imperial del Siglo de Orosupieron enriquecer y enriquecerse del trasvase cultural que por medio de las campañas militares se llevó a cabo en toda Europa, sin olvidar tampoco las campañas en África, los viajes a América, etc.

El Renacimiento español representa una era de expansión y de deseo de autorrealización nacional. Con la rendición de la Granada musulmana y con el descubrimiento de América, el dominio español se extiende hacia el Norte de África y hacia el Nuevo Mundo. Pronto a los hombres de armas se les planté una doble posibilidad para coronarse de gloria y honor militar: la primera, luchar contra los turcos o contra los adversarios europeos del Rey; la segunda, embarcarse hacia las tierras del Nuevo Mundo. Si en un principio les pareció una tentativa más suculenta la primera ${ }^{1}$, no obstante, muy pronto toman conciencia de que es responsabilidad española llevar la civilización cristiana a estos pueblos hasta entonces desconocidos.

Los dos reyes españoles encargados de realizar esta misión evangelizadora son Carlos V y su hijo Felipe II. El primero pretendió unificar la Europa cristiana, imprimiendo a sus campañas militares el sentido de Cruzadas; fue elegido emperador de Romanos en 1519 y ejerció este poder hasta 1556, año en que abdicó. En 1530 recibió de manos del Papa la corona imperial y se convirtió para españoles e italianos en todo un símbolo, en quien deposita- 
ron la confianza de la victoria sobre el turco y a quien confiaron la unificación de Europa, escindida por cuestiones religiosas. Mas después de treinta años de lucha, tuvo que renunciar a su propósito, asumir su fracaso, abdicar la corona de España en favor de su hijo y nombrar a su hermano Fernando sucesor en la Corona Imperial.

El reinado de Felipe II (1556-1598) se sustentó durante algún tiempo sobre la concepción de España como pueblo poderoso y feliz. El triunfo sobre los turcos en la batalla de Lepanto (1571) contribuyó al aumento de la euforia patriótica y aportó a los poetas un tema verdaderamente heroico que desarrollar en los cantos épicos y en las variadas poesías que surgieron ${ }^{2}$. Esta tan celebrada victoria sostendría la moral de los españoles en las derrotas posteriores: la batalla de Alcazarquivir (1578), el episodio de la Armada Invencible (1588), el saqueo de Cádiz por el conde de Essex (1596), etc.

El sentimiento patriótico, unido a la belicosidad, inunda el ambiente renacentista y de ahí que los poetas dediquen parte de su creación a la epopeya heroica, género que da cuenta del dinamismo guerrero de la época, pues no olvidemos que la literatura siempre ha sido un instrumento de poder $y$ que, desde los Reyes Católicos, ésta se venía usando como medio publicitario que propagaba las hazañas guerreras ${ }^{3}$.

Juan de Mena y el Marqués de Santillana son los antecedentes inmediatos del Renacimiento literario español. En ambos es común la preocupación por crear una poesía culta para España y en ambos se preconiza un objetivo providencialista: la unidad cristiana y política y la victoria sobre el infiel.

Juan de Mena reclamó en favor de los poetas que cantaban en lengua castellana el privilegio que poseían los antiguos de coronar de fama a sus héroes e inmortalizarlos por medio de la literatura. En su obra Laberinto de Fortuna, proclama su deseo de salvar del olvido las hazañas gloriosas de los ejércitos españoles. Este mismo celo patriótico se reflejará en cientos de poetas durante los siglos XVI y XVII.

La obra del Marqués de Santillana da cuenta también de su curiosidad intelectual y de su afán de modernidad. Poeta, político y soldado, estuvo al servicio de los reyes de Aragón, en cuya corte tomó contacto con los poetas catalanes de la época ${ }^{4}$ y con la literatura italiana. Compuso cuarenta y dos Sonetos fechos al itálico modo, aunque sin éxito, pues este metro no se afianza en España hasta que el embajador veneciano Andrea Navagiero (1526) convence a Boscán de la importancia de adaptar los metros italianos al castellano. No obstante, será el genio de su amigo Garcilaso el que logre con éxito la implantación de las formas renacentistas.

Aunque la expansión cultural de España se hizo sentir en Francia, Inglaterra y Alemania, la monarquía española sólo gobernó de hecho en Italia 
y en los Países Bajos. Italia era la maestra de los humanistas españoles, pues poseía muchas de las cualidades que los castellanos ambicionaban para sí, pues había sabido adaptar el mundo grecolatino al gusto literario de los tiempos modernos. A comienzos del siglo XVI, España sentía que en el mundo de las letras era inferior al mundo antiguo y a la Italia contemporánea. Este retraso se intentaba justificar, en la mayoría de los casos, por la plena dedicación durante años de los españoles a las armas en deterioro de las letras; en otras ocasiones, se atribuía a la ignorancia, a la pereza, a la falta de constancia, a la ausencia de mecenazgos, etc.

Así describe Fernando de Herrera en sus comentarios a la poesía de Garcilaso (1580) la situación de la poesía española con respecto a la italiana:

Que hayan sido ellos [los italianos] en este género más perfectos y acabados poetas que los nuestros, ninguno lo pone en duda; porque han atendido a ello con más vehemente inclinación, y han tenido siempre en grande estimación este ejercicio. Pero los españoles, ocupados en las armas con perpetua solicitud hasta acabar de restituir su reino a la religión cristiana, no pudiendo entre aquel tumulto y rigor de hierro acudir a la quietud y sosiego de estos estudios, quedaron por la mayor parte ajenos de su noticia; $y$ a pena pueden dificilmente ilustrar las tinieblas de la oscuridad, en que se hallaron por tan largo espacio de años. Mas ya que han entrado en España las buenas letras con el imperio, y han sacudido los nuestros el yugo de la ignorancia, aunque la poesía no es tan generalmente honrada y favorecida como en Italia, algunos la siguen con tanta destreza y felicidad, que pueden poner justamente envidia y temor a los mismos autores de ella. ${ }^{5}$

Si bien es cierto que en sus primeros contactos España fue principalmente receptora de la influencia italiana, no podemos olvidar que la cultura española supuso también un gran peso en Italia, pues fueron muchas las obras españolas leídas y traducidas a la lengua toscana. No obstante, la preocupación por nuestro retraso cultural llega hasta mediados del siglo XVI, cuando, en la cumbre del Siglo de Oro, España ha superado sus primeras impresiones de insuficiencia y no tiene duda de la mella que su literatura ha ocasionado en el mundo. De un modo distinto a Herrera describe, en 1609, Francisco de Quevedo la situación de nuestra lengua y de nuestra literatura en el capítulo cuarto de su obra denominada España defendida y los tiempos de ahora:

(...); más débese advertir primero que, como las naciones de las cuales, por la virtud y el valor, es España aborrecida, haciéndolas no con poca gloria suya invidiosas, viendo que no pueden negar a los españoles, el esfuerzo, la osadía en los peligros, la constancia en los trabajos, $y$, en fin, el primer lugar en las armas, acógense a negarlos las letras y a poner defectos, ya que no en los entendimientos y ingenios, en los juicios y en el trabajo y en la lengua, sin advertir, como se dirá largamente en su lugar, que no sólo en todo género de 
letras no nos han excedido ningunos pueblos del mundo; pero que son pocos los que en copia y fama y elegancia de autores en el propio idioma y en el extranjero nos han igualado, y que, si en alguna parte han sido más fértiles sus ingenios, ha sido en la que, por indigna de plumas doctas, capaces de may.ores estudios, hemos despreciado gloriosamente (...) ${ }^{6}$

No cabe duda de que si Quevedo sale a la defensa de la lengua y de la literatura españolas no es llevado tan sólo de su espíritu patriótico, sino fruto de que, desde que Herrera escribió las anotaciones a Garcilaso en 1580, y hasta 1609 , año en que escribe Quevedo su defensa, ha dado tiempo para hacer balance de las nuevas creaciones hispanas, en las que han jugado un papel fundamental esos poetas humanistas, cuya condición de soldados les ha hecho viajar $y$ enriquecerse de todo el ambiente cultural que respira Europa en el Renacimiento.

Hemos escogido a seis soldados-poetas españoles: Garcilaso de la Vega, Diego Hurtado de Mendoza, Hernando de Acuña, Gutierre de Cetina, Francisco de Figueroa y Francisco de Aldana. Todos ellos prototipos del ideal renacentista del El Cortesano de Castiglione, a través de los cuales valoraremos esta simbiosis cultural acontecida en el Renacimiento entre España y Europa.

Garcilaso de la Vega ${ }^{7}$ (Toledo, 1501 ó 1503 - Niza, 1536) aprendió latín según los nuevos métodos difundidos por Nebrija, música, esgrima y equitación. Influido profundamente por las corrientes erasmistas y humanistas, trabó amistad con Boscán y con la casa del duque de Alba. En 1523 recibió el hábito militar de Santiago. Tras una primera estancia en Italia y por asistir a unas bodas sin el permiso del emperador Carlos V, fue desterrado cerca del Danubio - a este episodio alude en la canción tercera- y, posteriormente, a Nápoles, donde intensifica sus conocimientos sobre el humanismo y la poesía italiana y donde escribe sus poemas más importantes. Combatió en la isla de Rodas, en Navarra contra los franceses, en Italia, en Túnez y murió precisamente a causa de una campaña militar en Niza (1536). Su educación humanística, sus contactos con la cultura italiana y su apego a las armas forjan su espíritu plenamente renacentista. Como representante de la fusión de las armas y de las letras, sólo escribía cuando su intensa vida militar se lo permitía, no obstante, los ecos guerreros son escasos en su poesía, cuyo tema con mayúsculas es el Amor. Esto queda justificado en su Canción Quinta (Oda "A la flor de Gnido"), cuando el poeta le dice a la dama que si su canto tuviera poder órfico no lo emplearía para cantar a la guerra sino a la belleza de la amada:

no pienses que cantado

sería de ml, hermosa flor de Gnido, 
el fiero Marte airado, a muerte convertido, de polvo y sangre y de sudor teñido;

ni aquellos capitanes en las sublimes ruedas colocados, por quien los alemanes el fiero cuello atados, $y$ los franceses van domesticados.

Mas solamente aquella fuerza de tu beldad sería cantada, y alguna vez con ella también sería notada el aspereza de que estás armada; (vv. 11-25)

$Y$ es que Garcilaso es un guerrero rendido al Amor, como cuenta a su amigo Boscán en el primer terceto del soneto XXVIII:

Sabed que en mi perfecta edad y armado con mis ojos abiertos me he rendido al niño que sabéis, ciego y desnudo. (vv. 9-11)

De las pocas alusiones que hay en su obra a episodios bélicos de su vida destacamos el soneto XXXV, escrito en 1535 desde la Goleta, donde fue herido:

Boscán, las armas y el furor de Marte, que con su propia sangre el africano suelo regando, hacen que el romano imperio reverdesca en esta parte,

han reducido a la memoria el arte y el antiguo valor italiano, por cuya fuerza y valerosa mano África se aterró de parte a parte.

Aquí donde el romano encendimiento, donde el fuego y la llama licenciosa sólo el nombre dejaron a Cartago,

vuelve y revuelve amor mi pensamiento, hiere y enciende el alma temerosa, y en llanto y en ceniza me deshago.

A pesar de que la obra del toledano - como su vida - es corta, a ella se debe el triunfo definitivo de las innovaciones traídas de Italia por Boscán, pues Garcilaso supo, partiendo de su inspiración italiana, fortalecer y renovar la propia poesía hispana, sin detrimento de la poesía castellana tradicional, pues, pese a que son las novedades italianas las que alcanzan las más altas cimas poéticas, ambas tendencias conviven y, por ello, no es extraño encon- 
trar fórmulas poéticas tradicionales junto a la técnicas y temas de la poesía italianizante. Muchos autores manifestaron el gusto por la dualidad, escribiendo elevadas composiciones al estilo italiano junto a otras de sabroso tono popular (sin duda, la poesía del siglo XV está presente e influye poderosamente en nuestros mejores poetas). De este modo, Garcilaso, al igual que Hurtado de Mendoza, Cetina, Acuña, etc., emplearon durante un tiempo las dos formas. Es muy probable que Garcilaso escribiera su Égloga tercera durante la campaña de Provenza (hacia 1536), en la que murió. En estos versos, de modo conciso, Garcilaso expresa su vida y sus afanes:

Entre las armas del sangriento Marte, do apenas hay quien su furor contraste, hurté de tiempo aquesta breve suma tomando, ora la espada, ora la pluma (vv. 37-40).

Pero no siempre es fácil la armonía. En la Elegía I, dedicada al duque de Alba en la muerte de Don Bernaldino de Toledo, hay unos versos en los que destaca la nota personal y biográfica del poeta, que se cuestiona el sentido de la guerra:

¿Qué se saca de aquesto? ¿Alguna gloria?

¿Algunos premios o agradecimientos?

Sabrálo quien leyere nuestra historia:

veráse allí que como polvo al viento

así se deshará nuestra fatiga

ante quien se endereza nuestro intento. (wv. 91-96)

En unos versos de la Elegía II el poeta se muestra en contradicción con el guerrero y nos informa del presentimiento de su cercana muerte:

¡Oh crudo, oh riguroso, oh fiero Marte,

de túnica cubierto de diamante,

y endurecido siempre en toda parte!

¿Qué tiene que hacer el tierno amante

con tu dureza y áspero ejercicio

llevado siempre del furor delante?

Ejercitando, por mi mal, tu oficio, soy reducido a términos que muerte será mi postrimero beneficio.

$Y$ ésta no permitió mi dura suerte que me sobreviniese peleando, de hierro traspasado agudo y fuerte,

por que me consumiese contemplando mi amado y dulce fruto en mano ajena

$y$ el duro posesor de ml burlado. (vv. 94-108) 
Diego Hurtado de Mendoza ${ }^{8}$ (Granada, 1503-Madrid, 1575) es otro autor prototipo del humanista renacentista; se dedicó en sus horas de ocio a las artes plásticas, las humanidades, la poesía, el coleccionismo de antigüedades y manuscritos,...; posela grandes dotes: perspicacia, habilidad, capacidad de persuasión, gracia personal,... Desarrolló su formación en Granada, Salamanca e Italia. Precisamente durante su estancia en este país reunió una importante biblioteca que donó al rey. Sus manuscritos griegos y latinos se conservan en la Biblioteca del Escorial. Fue más famoso como diplomático que como soldado. Como político sirvió al emperador y fue embajador español en Inglaterra, Venecia y Roma, donde participó en el Concilio de Trento. Por una disputa palaciega estuvo desterrado en Granada, donde intervino en la rebelión de los moriscos y escribió la Guerra de Granada (publicada en Lisboa en 1627), obra en la que describe las causas del conflicto y denuncia la actuación de la casa real hacia los Mendozas, representantes de la vieja nobleza, que venían gobernando Granada tradicionalmente y que ahora estaban siendo sustituidos por gente nueva.

Mendoza escribió poesía castellana de carácter cortesano, muy próxima a la poesía de cancionero, así como también poesía de tipo italianizante. $\mathrm{Al}$ igual que Garcilaso, su tema dominante es el amor mientras que las alusiones a su vida como militar o diplomático escasean. No obstante, una de las epístolas (la $\mathrm{n}^{\circ} \mathrm{V}$ ) a Don Luis de Ávila, soldado, historiador y diplomático que vivió con intensidad la vida imperial, ha podido fecharse hacia 1540, gracias a una breve referencia a datos históricos:

No se cura de bueno o mal partido que hagan con el turco venecianos, ni que venza el Sofl 9 o que sea vencido. (vv. 25-27)

Se está aludiendo al momento en que venecianos y turcos buscaban un arreglo de paz, cuando Solimán II el Magnífico no se había anexionado aún Persia.

Posteriormente, en esta misma epístola, se incluye un elogio al emperador Carlos V:

Tú sirve al sefior que has elegido, acompana en presencia sus vitorias y el nombre por las gentes extendido.

Mira cómo nos muestra las memorias de los que todo el mundo sojuzgaron imitando sus títulos y glorias.

Él pasará por donde no pasaron las banderas y griegos escuadrones, y volverán por donde no tornaron. (vv. 100-108) 
A continuación, el emperador es identificado con Alejandro Magno, pues ambos se constituyen en un símbolo del poder que contrasta con el ideal de aurea mediocritas que anhela el poeta:

Otro mundo es el mío, otro lugar, otro tiempo el que busco, y la ocasión de venirme a mi casa a descansar.

Yo viviré la vida sin pasión, fuera de desconcierto y turbulencia, sirviendo al rey por mi satisfacción.

Si conmigo se extiende su clemencia dándome con que viva en medianeza, holgaréme y, si no, terné paciencia. (vv. 154-162)

En otra epístola a Don Luis de Ávila (la no VI), Mendoza alude a los preparativos de la expedición de Argel y a la posible cruzada a Siria, hechos que datan el texto antes de 1541, momento de constante movilidad de Carlos V por el Mediterráneo. En la composición se describe, además, la vida del embajador, lo que sugiere una fecha próxima a la llegada de don Diego a Venecia (1539). El autor reitera de nuevo el tópico del aurea mediocritas y huye, entre otras cosas, del sangriento dios de la guerra, Marte, y de las mallas defensivas:

no el sangriento señor de las batallas.

¿Qué tengo yo que ver con las estrellas,

con los rayos, los tiempos o las mallas? (vv. 121-123)

Mendoza dedica una epístola a su hermano más próximo, Bernardino, militar que intervino en la guerra contra los comuneros (1520), en la conquista de Túnez, en la batalla de Alborán (1540), en las campañas de Argel y del Rosellón, en la batalla de San Quintín (tras la cual murió). Llama la atención que no hay referencias a la vida militar en todo el texto, sino que el autor se limita a darnos detalles de su vida privada y cotidiana.

Sin embargo, en una epístola a don Diego Lasso (la $\mathrm{n}^{\circ} \mathrm{XI}$ ), embajador de Fernando I de Bohemia en Roma al mismo tiempo que Hurtado lo era de Carlos I, Mendoza alude a la actividad no perecedera del soldado ni siquiera en su vejez:

Colgadas ya las armas en el templo, torna el viejo soldado a la porffa por ira, por virtud o por ejemplo. (vv. 13-15)

Quizás el soneto que de un modo más claro manifiesta el deseo de conquista del Oriente y la superioridad de Carlos V sobre el enemigo turco es el 
que comienza "Domado ya el Oriente, Saladino". Mas el texto se apoya en referencias a batallas o a acontecimientos militares del pasado, como la posible alusión del verso 10 a la derrota de los cruzados de Hattim, comandados por Luis VII de Francia (1147) o el comentario final al asesinato de Pompeyo (48 a. J. C.).

Por último, destacamos el soneto LVII, de influjo petrarquista, en el que Hurtado, mediante la repetición de la anáfora ahora, va aludiendo a las distintas actividades a que suele dedicarse -entre ellas la poesía y las armas - para proclamar que, haga lo que haga, llevará siempre en su corazón la imagen de su amada:

Ahora en la dulce ciencia embebecido, ahora en el uso de la ardiente espada, ahora con la mano y el sentido puesto en seguir la caza levantada,

ahora el pesado cuerpo esté dormido, ahora el alma atenta y desvelada, siempre en el corazón tendré esculpido tu ser y hermosura entretallada. (vv. 1-8)

Hernando de Acuña ${ }^{10}$ (¿Valladolid, 1518 - Granada, 1580?), poeta, soldado y diplomático, es también prototipo del poeta-soldado renacentista, capaz de combinar la dedicación militar con la afición por las letras. Contó con la confianza del emperador Carlos $\mathrm{V}$ y, posteriormente, con la de Felipe II. En el Memorial de D. Hernando de Acuña a Felipe II, quiso dejar constancia de su participación en hechos heroicos notables desde su llegada a Italia hasta la batalla de San Quintín, así como de su estancia en Gravelinas. Debido a la fama de poeta de que ya gozaba entre sus contemporáneos, Carlos V le encargó adaptar en verso la traducción en castellano que el propio emperador había hecho de $E l$ caballero determinado, de Oliver de la Marche. Acompañó al emperador en varias campañas militares e hizo de mediador diplomático en el conflicto de la plaza fuerte de África, próxima a Túnez. En los primeros meses del reinado de Felipe II permaneció como soldado activo, participando en la batalla de San Quintín y en el desastre galo ante Gravelinas. Tras su vuelta a España, contrajo matrimonio e inició una vida retirada, impregnado por el desengaño. Envuelto en la indigencia se dedica a solicitar recompensas en nombre de sus hazañas militares. Aunque murió olvidado del dios Marte, al parecer Apolo no le negó su protección, pues progresivamente se fue elevando su fama poética.

Las intervenciones militares en África, Italia y Alemania, e incluso la estancia en la cárcel, no fueron óbice para interrumpir la labor literaria de 
Acuña, sino que, por el contrario, son varios los poemas en los que se trasluce su experiencia militar. Su soneto XCIV, dedicado Al Rey Nuestro Señor, es uno de los más famosos del siglo XVI. De raíz imperialista, muestra el ideal humanista de una monarquía ecuménica. Se escribió probablemente en 1547 para glorificar al Emperador por el triunfo sobre los luteranos tras la victoria de Mühlberg. En el famoso endecasílabo trimembre que cierra el segundo cuarteto, Acuña pregona un Monarca, un Imperio y una Espada. El texto posee un carácter mesiánico (fiet unum ovile et unus pastor: 'habrá un solo rebaño y un solo pastor'), cuya inminencia se pone de manifiesto por medio de la triple anáfora del adverbio temporal "ya":

Ya se acerca, Sefior, o es ya llegada la edad gloriosa en que promete el cielo una grey $y$ un pastor solo en el suelo, por suerte a vuestros tiempos reservada;

ya tan alto principio, en tal jornada, os muestra el fin de vuestro santo celo, y anuncia al mundo, para más consuelo, un Monarca, un Imperio y una Espada;

ya el orbe de la tierra siente en parte y espera en todo vuestra monarquía, conquistada por vos en justa guerra, que a quien ha dado Cristo su estandarte, dará el segundo más dichoso día en que, vencido el mar, venza la tierra.

En su Epigrama a la muerte del emperador Carlos V. Acuña elogia la grandeza humana y política del emperador con el mismo espíritu militar, político-imperialista y mesiánico-religioso del texto anterior. El epigrama está puesto en boca de la Fama y se construye sobre el tópico de que se perdura en la memoria por las hazañas cometidas. Los versos $51-60$ se refieren a las luchas entre las fuerzas de Solimán II. Los versos 71-80 aluden a la campaña contra los protestantes, agrupados en la liga de Smalkalda. De los versos 81 al 90 nos encontramos ante un poema de circunstancias, mediante el cual Acuña trata de ganarse el favor de Felipe II. Las dos últimas quintillas presentan a Carlos V doblegando su alma únicamente ante Dios, para concluir proclamando que el emperador ha conquistado la salvación eterna y la eterna fama".

Este otro fragmento de una égloga de Acuña (el texto IV) da cuenta de ese binomio (arma-pluma) en el que se debate su vida, binomio que le valió el sobrenombre de "capitán poeta":

Era su fundamento honroso celo $y$, siguiendo de Marte el ejercicio con el ardiente sol y el crudo yelo, 
se aplicó de tal suerte al duro oficio, que en él $y$ en todo siempre se ha mostrado sujeto a la virtud, libre de vicio.

$Y$, con seguir este arte, no ha olvidado la de Apolo y la musas, ni se olvida del trato pastoral ni del ganado, (vv. 100-108).

La armonía entre estos dos mundos tan distintos se manifiesta aún de un modo más claro en el soneto XIV, que presentamos a continuación. Acuña en el primer terceto, como su maestro Garcilaso (estrofa quinta de la Égloga III), dedica parte de su tiempo a las armas y parte al ejercicio poético, para sobrellevar sus momentos de soledad:

Atenta al gran rumor la musa mía del armigero son de Marte fiero, cesó del dulce estilo que primero en sujeto amoroso se extendía;

mas hora, con la vuestra en companía, me vuelve al sacro monte, donde espero levantarme más alto $\mathrm{y}$, por grosero, dejar con nuevo canto el que solía.

Así sus horas con la espada a Marte, y los ratos del ocio con la pluma pienso, señor, enderezar a Apolo;

dando a los dos de mí tan larga parte, y tomándola dellos tal, que en suma no me cause tristeza el verme solo.

En este otro fragmento (texto CIV), Acuña se muestra tajante en su deseo de simultanear la actividad militar con la poética:

Jamás pudo quitarme el fiero Marte, por más que en su ejercicio me ha ocupado, que en medio de su furia no haya dado a Apolo de mi tiempo alguna parte; (wv. 1-4)

El hecho de que Carlos V se negara a ceder el ducado de Milán, desencadenó una nueva guerra con Francia, que culminó en la derrota de Cerasola (1544), en la que murieron más de ocho mil soldados españoles y fueron hechos prisioneros seiscientos, entre ellos Acuria, quien, durante los cuatro meses que duró su estancia en la prisión de Narbona, escribió tres sonetos dedicados a su amada. En el primero de ellos (el $n^{\circ} \mathrm{LXI}$ ) se explicita la derrota:

así, después que por contraria via volvió su rueda, y con el fiero Marte, sin que cese su furia ni se aparte de mí, los dos me dañan a porfía, 
ni su poder ni la prisión francesa,

do por nuevo camino me han traído,

privarán de su bien mi pensamiento; (vv. 5-11).

De Acuña queda destacar el texto denominado La contienda de Ayax Telemanio y de Ulises sobre las armas de Aquiles ( $\mathrm{n}^{\circ} \mathrm{VI}$ ), en el que la simpatía que el autor deja ver hacia el héroe es reflejo de su posición como militar.

Gutierre de Cetina ${ }^{12}$ nació en Sevilla en 1520 , donde se educó. Prototipo también del soldado-poeta, participó en campańas militares en Italia, Francia, Alemania y Méjico -donde murió violentamente en 1557-. Mantuvo una estrecha amistad con otros dos poetas-soldados de su tiempo, Diego Hurtado de Mendoza y Baltasar de Alcázar. En Italia contó con la ayuda del príncipe D'Ascoli, mecenas a quien dedicó varios sonetos y una epístola. Durante su estancia en Méjico escribió algunas obras dramáticas perdidas, así como parte de su obra lírica ${ }^{13}$, y es fácil imaginar la gran influencia que ejerció, pues fue el primer poeta de la escuela italianizante que llegó al Nuevo Mundo. ${ }^{14}$

$\mathrm{Al}$ artista y poeta Francisco Pacheco debemos las escasas noticias biográficas de este autor. Dice Pacheco en un fragmento sobre Cetina:

diose después de sus estudios al arte militar en que fue no menos valiente Soldado que estremado Poeta. Siéndole tan agradable la caxa de Marte como la vigüela de Apolo. Gastó en esta profession los años de su juventud en Italia, y llamándole su Divino ingenio se volvió a su Patria a la quietud de las Musas $(. . .)^{15}$

Aun cuando Cetina prefirió cantar más al amor que a la guerra, compuso una serie de textos que están ambientados en el mismo fragor de la batalla y otros que son elogios de las hazanas militares de varias personalidades contemporáneas suyas. Al Conde de Feria, por ejemplo, dedicó dos sonetos alabando sus acciones guerreras; en la epístola a don Diego Hurtado de Mendoza (XIV) también se hace alusión al mismo conde:

Pensé deciros del novel de Feria cómo con su valor ha desterrado desta corte los vicios y miserias,

Y cómo en cuatro pasos ha alcanzado los que primero dél corrieron tanto, y algunos, o los más, atrás dejado. (157-162)

La epístola $A$ don Diego Hurtado de Mendoza puede fecharse hacia 1543, pues Cetina dice estar escribiendo el texto en el mismo año del asalto y toma de Dura (24 de agosto de 1543), victoria considerada como una de las más grandes de la vida militar de Carlos V. Dice así: 
Será el sujeto, pues, de aquella honrosa empresa en que este año ha César hecho, tanto como dificil, gloriosa.

Ver un tirano en dos horas deshecho, tan fuerte y atrevido, que hacía a los mayores que él tremer el pecho.

No vencido de amor y cortesía, Ni Fortuna en vencerle tuvo parte, mas de solo valor y gallardía.

Alli era de notar el nuevo Marte, Fernando 16, capitán de aquesta guerra, el ánimo, el valor, ingenio y arte;

Alli se vio en el sitio de una tierra, Dura de nombre, asaz dura y extraña, Si en ánimo espafiol virtud se encierra.

Con razón memorar puedes, joh Espafia! entre las otras tantas memorables, ésta, que no será menor hazaña. (52-69)

El texto continúa narrando los acontecimientos de la batalla y las consecuencias del asalto: los cadáveres, los heridos, el incendio, etc., en una descripción muy dinámica, en la que el autor se coloca como testigo inmediato para conseguir dar realismo a los acontecimientos y un mayor realce al ejército vencedor. En esta misma epístola Cetina cuenta las hazañas del ejército imperial, censurando a Carlos V por haber dejado escapar a Francisco I de Francia.

En el soneto XIV, al parecer dirigido a don Alonso de Ávalos 17, Marqués del Vasto, Cetina invita al militar a imitar a César escribiendo sus propias hazañas militares para inmortalizarlas:

A imitación de César con la pluma, mientras que reposar dejáis la espada, haced eterna vos vuestra memoria. (vv. 12-14)

A la esposa de don Alonso, la Marquesa del Vasto, dedica el soneto LVI con motivo de su llegada a Liguria, celebrando las acciones militares de su esposo, muerto en 1546:

Si de dolor te queda alguna parte, sea por no haber visto en companía de la nueva Diana al nuevo Marte. (vv. 12-14)

Al Duque de Sessa dedicó el soneto XXXI, en el que le recuerda las glorias de su abuelo, el Gran Capitán, y el soneto CXCI, en el que celebra la venida del Duque a las orillas del Betis.

También dedica Cetina una estancia, una epístola y un soneto a don Jerónimo de Urrea (CXII), militar y poeta que se distinguió en varias haza- 
ñas militares, entre ellas, la toma de Dura, y cuyo nombre poético era Iberio. En el soneto se ensalzan sus empresas guerreras y, sobre todo, su valor militar, al que es imposible dar muerte.

De los diez sonetos dedicados al Príncipe de Áscoli, destacamos el LXI, en el que se elogia su inmortal espíritu guerrero:

Estos escudos de armas, los trofeos, las memorias que veis en cada parte, Príncipe digno de inmortal historia, despertadores son de los deseos que a un hijo tal cual vos del nuevo Marte harán subir a la paterna gloria. (vv. 9-14)

Aunque todavía podemos rastrear más textos que dan cuenta del ambiente guerrero, no queremos pasar por alto el elogio al emperador Carlos $V$, soneto CXLVIII, al que se compara con Hércules:

No fuera Alcides, no, famoso tanto ni durara en el mundo hoy su memoria, si menos cara hubiera la victoria de los monstruos que aun hoy causan espanto.

La fuerte emulación con todo cuanto contrasta casi al par con vuestra gloria, harán al fin, Señor, que vuestra historia nos dure con eterno e inmortal canto.

El vencer tan soberbios enemigos, sujetar tantos monstruos, tanta gente, con el valor que el cielo en vos derrama, al siglo por venir serán testigos del honor que dará perpetuamente a Carlos Quinto Máximo la fama.

Las alusiones a los lugares o los nombres de río nos proporcionan en muchas ocasiones las claves para conocer dónde y en qué circunstancias fueron escritos los textos. Sirva como ejemplo, la canción XI que comienza:

Sobre las ondas del furioso Reno, lleno de nieves, turbio, helado y frío, al pie de un seco salce en la ribera, mientras Marte al furor daba un desvío,... (vv. 1-4)

Digno de ser destacado es el soneto $A$ los buesos de los españoles muertos en Castelnovo, quizás surgido de la contemplación directa del propio poeta que pudo, durante las guerras de Alemania, visitar esta población y divisar el horrible escenario de los tres mil soldados sacrificados por los turcos:

Héröes glorïosos, pues el cielo os dio más parte que os negó la tierra, bien es que por trofeo de tanta guerra se muestren vuestros huesos por el suelo. 
Si justo desear, si honesto celo en valeroso corazón se encierra, ya me parece ver, o que sea tierra por vos la Hesperia nuestra, o se alza a vuelo.

No por vengaros, no, que no dejastes a los vivos gozar de tanta gloria, que envuelta en vuestra sangre la llevastes,

Si no para probar que la memoria de la dichosa muerte que alcanzastes se debe envidiar más que la victoria.

Son escasos los datos biográficos sobre Francisco de Figueroa ${ }^{18}$. Debió nacer en Alcalá de Henares alrededor de 1536 y morir allí mismo en torno a 1617. Procedente de una familia hidalga, estuvo al servicio de las armas y viajó a Italia, donde entró en contacto con el humanismo y las corrientes petrarquistas y donde empeź a destacar tanto como poeta que escribía en castellano como en toscano. Fue en Siena donde, influenciado por el ambiente cultural de la ciudad, afianzó su vocación lírica y maduró su saber poético, participando en tertulias y academias en las que se lelan a los clásicos Dante, Petrarca, Bembo, Boccacio. A partir de 1555 interrumpió ese difícil equilibrio armas-letras y se inclinó a favor de la práctica intelectual que le ofrecía la sociedad cortesana de Siena. Tras abandonar Italia y con su vuelta a España participa del sedentarismo cortesano impuesto por la burocratización que emana de la personalidad de Felipe II. A partir de 1570 paś́ a ser más un burócrata que un poeta; convertido en secretario cortesano y, falto ya del estímulo que supone un entorno intelectual, se consagró a sus deberes y redujo considerablemente su dedicación a la poesía, que sólo tendrá un carácter externo y ocasional. En 1571 la Universidad de Salamanca convocó un certamen poético para celebrar la victoria de Lepanto y el nacimiento del Príncipe don Fernando, hijo de Felipe II y doña Juana de Austria; Figueroa participó con su soneto CXVII, que, a pesar de su fama como poeta, pasó sin pena ni gloria:

Si el movedor eterno prometiera en las famosas prendas ya perdidas felicidades tan enriquecidas que igual la gloria con el daño fuera,

la suerte que es mejor se escureciera de las fortunas más engrandecidas que están eternizándose esculpidas con claro nombre en la más alta esfera.

Mas dar a Espafia, tras un don tan grande que no hay quien armas en su ofensa tome según su fuerza victoriosa admira, 
un Príncipe quel mundo rija y mande

y el bárbaro rigor al yugo dome:

falta el juicio si a entendello aspira.

En 1578 va a Flandes con el duque de Terranova para combatir la oposición de la nobleza flamenca al dominio español; no obstante, las negociaciones resultaron infructuosas y Figueroa es enviado al frente, donde presencia la masacre cometida por ambos bandos; este hecho se trasluce en su canción CXIX, que debió ser compuesta hacia 1579, tras su regreso de la campaña de Flandes; en ella, siguiendo el tópico horaciano del simbolismo de la nave ${ }^{19}$ expresa un taedium vitae y una actitud desengañada ante la vida militar y política que ya se muestra inútil para el poeta, que advierte así a la nave:

No, no. Tente a la tierra,
o ya, si al agua has vuelto,
mira no salgas de seguro abrigo.

¿No ves rota la guerra?

¿No ves a Bóreas suelto,

y que Orión armado, tu enemigo,

vendrá a embestir contigo?

Y estarás tú muy buena

desclavado el timón, rota la entena. (wv. 28-31)

(...)

¿No ves que, aunque corrieses

el mar de parte a parte,

dando caza a flotas enemigas,

$y$ las unas rompieses

por fuerza, otras con arte

hicieses declarar por tus amigas,

de tan graves fatigas,

el galardón más cierto

será encallar al embocar del puerto? (vv. 55-63)

(...)

Figueroa mereció entre sus contemporáneos el sobrenombre de "el Divino". Su poesía conoce dos caminos diferentes: el amoroso y el religioso, aunque este último es de escasa importancia. Se le ha considerado un poeta manierista, cuya estética manifiesta la transición entre el Renacimiento y el Barroco. Al igual que tantos coetáneos suyos practica las dos métricas (la tradicional y la petrarquista), que se dan a lo largo de su vida simultáneamente. Sin embargo, en su corpus lírico está prácticamente ausente la tópica tensión armas/letras. Las dos primeras liras de la composición LIII suponen la excepción que confirma la regla: 
Habiendo de partirse

un pastor de este monte y su ribera

comienza a despedirse

con voz tan lastimera,

que el áspide más duro enterneciera.

Resuena de tal arte

su zampona amorosa y caramillo,

que al belicoso Marte

de solamente ofllo

rindiera su fiereza al pastorcillo. (vv. 1-10)

Estos versos pudieron ser escritos antes de la partida del poeta a Italia. Lo más curioso es que - mediante la evocación al mito de Orfeo y al poder sereno de la música - se anuncia ya el triunfo de Apolo sobre Marte, lo que se confirmará ciertamente en la experiencia vital de Figueroa, que abandonará la vida guerrera y optará por las letras.

Como poeta-soldado en esta selección no podría faltar Francisco de Aldana ${ }^{20}$. Nació en 1537, probablemente en Nápoles ${ }^{21}$, donde su padre era capitán profesional; creció como protegido de los Médicis, en el ambiente renacentista de Florencia, donde se forjó en la cultura humanista y se familiarizó con los textos de Ovidio y Horacio. Dominó el italiano hasta el extremo de ser considerado un poeta bilingüe. Se hizo soldado profesional, consiguió el grado de capitán y luchó en los Países Bajos (1567-1576) a las órdenes del Duque de Alba, una de las figuras más importantes de la política del imperio español, cortesano renacentista e hidalgo español que luchaba por la primacía de la Iglesia y de la corona hispánica. En 1572 acompańb, como sargento mayor, a don Juan de Austria en su segunda expedición contra los turcos. Vivió los desastres de la guerra para las tropas españolas en los sitios de Harlem (1572-1573), Alkmaar (1573) y Leiden (1574). Murió con el rey don Sebastián de Portugal en la batalla de Alcazarquivir (1578). Por su vida, Aldana quedó como un símbolo del intelectual de su tiempo y fue muy prestigioso para los autores posteriores. Por su muerte, se convirtió en personaje literario en varias versiones sobre el tema de Alcazarquivir. ${ }^{22}$

Contrastan en su poesía, por un lado, sus poemas ascéticos, en los que impera un fuerte anhelo de paz de espíritu y de vida retirada y contemplativa; por otro, sus poemas imperiales, los cuales dan cuenta de la realidad bélica que vive el poeta. Su cruda experiencia militar le hizo, sin duda, perder su ambición personal de gloria militar y su entusiasmo por las actividades guerreras y le acrecentó el deseo horaciano de vida retirada.

En su Epístola III, escrita tras la victoriosa campaña militar contra el conde Luis de Nassau-Dillenburgo, Aldana glorifica la vida soldadesca, enfa- 
tizando la virtud varonil en la batalla y realzando el sudor y la sangre como símbolos de valentía en las dinámicas descripciones de los violentos combates:

yo de honroso sudor cubro mi cara

y de sangre enemiga el brazo tiño

cuanto con más furor muerte dispara. (vv, 10-12).

Esta actitud contrasta con la del poema XI, Otavas del mismo capitán Aldana sobre el bien de la vida retirada, en el que se condena la vida militar:

No de Marte feroz, bravo, impaciente

veré la confusión, la muerte y pena,

ni veré que mi espada se ensangriente

de propria sangre o de la sangre ajena;

ni en medio del verano más ardiente, cuando Aquilon su helado soplo enfrena, sin aliento, sin vida y sin sentido, verme he de sangre y de sudor tefiido. (vv. 248-255)

La Epístola VI, Carta para Arias Montano, versa sobre el tópico del "Beatus Ille". Aldana muestra sinceramente su soledad, declara los sufrimientos y ambiciones de su carrera militar y rechaza las circunstancias bélicas en que se encuentra:

Oficio militar profeso y hago, ¡baja condenación de mi ventura!, que al alma dos infiernos da por pago:

Los huesos y la sangre que Natura me dio para vivir, no poca parte dellos y della he dado a la locura, mientras el pecho al desenvuelto Marte tan libre di que sin mi daño puede, hablando la verdad, ser muda el arte; y el rico galardón que se concede a mi (llámola así) ciega porfía es que por ciego y porfiado quede.

No digo más sobre esto, que podría cosas decir que un mármol deshíciese en el piadoso humor que el ojo envía, y callaré las causas de interese (no sé si justo o injusto) que en alguno hubo porque mi mal más largo fuese; (vv. 13-30)

A continuación nos transmite sus proyectos inmediatos de seguir una vida retirada y llegar al hombre interior, única via hacia Dios (vv. 46-57); pero quizás el aspecto más importante sea el modo en que consigue unir el espíritu de la España de su época y su anhelo personal de unión mística. Mediante una bella metáfora iguala la conquista del Nuevo Mundo - con su 
tesoro de almas para la Iglesia y de oro y plata para la corona española- con la conquista personal de la santidad:

¡Oh grandes, oh riquísimas conquistas

de las Indias de Dios, de aquel gran mundo

tan escondido a las mundanas vistas! (vv. 274-276)

En el poema XVII, Otavas dirigidas al rey don Felipe, Aldana expresa, mediante una personificación alegórica, las amenazas que rodean al Imperio español, debidas principalmente a los moros, a los turcos y a los ingleses, $y$ aconseja al rey que luche contra el enemigo para consolidar las fronteras del Imperio. En una de las octavas alude a la herida que recibió en el sitio de Alkmaar:

\author{
Mas dudo, jay triste!, a Belgia, cuyo suelo \\ quiero y puedo afirmar no vanamente \\ haber de sangre yo rebelde al Cielo \\ tefiido alguna vez, con ira ardiente; \\ otra después quedó mi frágil velo \\ tendido en él con húmida corriente \\ del mismo humor, según o mala o buena \\ voluntad del destino al hombre ordena. (vv. 549-556)
}

A este mismo acontecimiento alude el denominado Diálogo entre cabeza y pie, escrito por el capitán Aldana siendo berido de un mosquetazo en un pie sobre Alquemar en Flandes, sirviendo el oficio del general de la artilleria. Este texto incompleto es una de las escasas composiciones en copla de arte menor que compuso Aldana. Mediante la discusión entre un pie herido en batalla y la cabeza, sobre cuál de los dos es el culpable de la herida, el poeta convierte esta copla en una parodia de la lucha entre el que manda y el que obedece, o entre el instinto y la razón, con lo que muestra el carácter arbitrario de muchas de nuestras acciones.

$Y$ como es de rigor, no puede faltar el elogio al rey, por lo que Francisco de Aldana, en su soneto XXVII, atribuye a Felipe II el papel mesiánico de unificar la cristiandad bajo la corona española.

De distinto matiz es el soneto $\mathrm{XXX}$, que ha suscitado diversas interpretaciones, según se haya entendido el último endecaślabo como irónico o no:

Otro aquí no se ve que, frente a frente, animoso escuadrón moverse guerra, sangriento humor teniir la verde tierra, y tras honroso fin correr la gente;

éste es el dulce son que acá se siente "España, Santïago, cierra, cierra!" y por süave olor, que el aire atierra, humo de azufre dar con llama ardiente; 
el gusto envuelto va tras corrompida agua, y el tacto sólo apalpa y halla duro trofeo de acero ensangrentado, hueso en astilla, en él carne molida, despedazado arnés, rasgada malla: joh solo de hombres digno y noble estado!

Si entendemos el texto como una amarga ironía, el poeta-soldado está dejando constancia del conflicto íntimo en el que se debate: el ansia de paz y de descanso frente a las actitudes bélicas de su circunstancia vital. Las imágenes sobre los desastres de la guerra, que atañen a los cinco sentidos en el orden de vista, oído, olfato, gusto y tacto, se cubren de dramatismo en cuanto que el denunciante es un testigo presencial que da autenticidad al texto.

Los sonetos XXXI, XXXII, XXXIII y XXXIV se alejan del sarcasmo del soneto anterior para, en términos subjetivos y religiosos, manifestar el deseo del poeta de escapar de su destino y elevarse místicamente. Estos textos coinciden en mostrarnos la lucha interior de un poeta que se debate entre contrarios, preludiando las actitudes barrocas que ya empiezan a surgir en la España de finales del XVI.

\section{CONCLUSIONES}

Finalmente, resumiré las características comunes a estos poetas-soldados seleccionados del Renacimiento español y que son, sin duda, extensibles a otros que no figuran aquí por cuestión de espacio:

- En primer lugar, estas personalidades, siguiendo las premisas de $E l$ Cortesano de Castiglione, entregan sus vidas a uno de los más significativos sinos de su época: el ejercicio de las armas y el cultivo de las letras.

- En segundo lugar, su dedicación al mundo de las letras es fruto de una actitud vital derivada del contexto cortesano que se vive y de los cánones socioculturales que exigen el otium como condición necesaria para la actividad intelectual.

- En tercer lugar, proceden, en general, de familias nobles y son cortesanos que se forman en los studia bumanitatis y dedican su vida al servicio del emperador Carlos V, por medio de la milicia o de la diplomacia. Y participar en la política imperial conlleva viajar a Italia, lo que supuso para todos una gran experiencia formativa.

- En cuarto lugar, compusieron parte de su obra en el extranjero $y$, muchos de ellos, incluso tradujeron al español obras importantes ${ }^{23}$. 
- En quinto lugar, todos se incluyen en la revolución poética que supuso la poesía petrarquista pero sin que, por ello, abandonen el caudal tradicional, que sigue fluyendo, enriquecido ahora por las nuevas tendencias. Y de la simbiosis producida dará cuenta el siglo XVII, momento en que las formas tradicionales adquieren un auge espléndido.

- En sexto y último lugar, todos prefirieron consagrarse a la poesía amorosa, mientras que el aspecto bélico, a pesar de que en él se debatían sus vidas, queda relegado cuantitativamente a un espacio bastante marginal en sus obras. Sin duda, intentaron recuperar el tiempo, perdido en las constantes campañas militares y no empleado en el amor, por medio de ese espacio eterno que ofrece la poesía. Y qué mejor espacio se le puede ofrecer a un hombre, que, envuelto en el ambiente ruidoso de una batalla, encuentra un rato de ocio y soledad. 


\section{NOTAS}

1 Será a partir de la llegada de Hernando Pizarro (1534) cuando los espafioles comiencen a ilusionarse por viajar a las Indias espafiolas, hasta tal punto que el descubrimiento se convertirá en un símbolo literario de la mentalidad ibérica, imagen de riqueza, tesoros y abundancia.

2 Basta recordar la Canción por la victoria de Lepanto de Fernando de Herrera, inspirada en el cántico de Moisés cuando el pueblo de Israel cruzó el Mar Rojo.

3

No olvidemos el papel fundamental que desempefiaron en este sentido los juglares en la Edad Media.

Desde finales del siglo XIV, Cataluña habfa servido de puente a la Italia renacentista.

Gallego Morell, Antonio (ed.), Garcilaso de la Vega y sus comentaristas. Obras completas del poeta acompaniadas de los textos integros de los comentarios de El Brocense, Fernando de Herrera, Tamayo de Vargas y Azara, Madrid, Gredos, 1972, 2a ed., pág. 313.

6 Don Francisco de Quevedo y Villegas, Obras completas en prosa, Madrid, Aguilar, 1986, 6a ed., pág. 563.

7 Garcilaso de la Vega, Poesta castellana completa, edición de Consuelo Burell, Madrid, Cátedra, $1984,10^{2}$ ed.

8 Diego Hurtado de Mendoza, Poesía, edición de Luis F. Díaz Larios y Olga Gete Carpio, Madrid, Cátedra, 1990.

9 Título religioso de la dinastía persa descendiente de Safi-ed-Din.

12 Hernando de Acuña, Varias Poestas, edición de Luis F. Diaz Larios, Madrid, Cátedra, 1982.

11 El poema II muestra también la admiración por el emperador que siente Acufía.

12 Gutierre de Cetina, Obras, edición de D. Joaquín Hazafias de la Rúa, México, editorial Porrúa, 1977.

13 Parte de la poesía lírica de Cetina se conserva en la Biblioteca Nacional de Madrid en Flores de varia poesta, obra recopilada en México en 1577: 69 sonetos, 2 canciones, 2 estancias, una elegía, un madrigal y 3 octavas.

14 Francisco de Terrazas fue uno de los primeros poetas criollos que estuvo bajo la influencia de Gutierre de Cetina.

15 Francisco Pacheco, Libro de descripción de verdaderos Retratos de Ilustres y memorables varones, en Guillermo Diaz Plaja, Antologia Mayor de la Literatura Española, vol. II, Renacimiento (Siglo

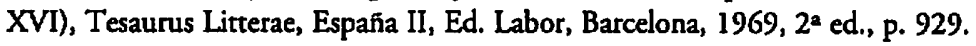

16 Se refiere al Duque de Alba a quien Cetina dirige varios sonetos.

17 Don Alfonso de Ávalos sirvió a las órdenes de su tó el Marqués de Pescara, posteriormente, en la flota de Moncada, donde cayó prisionero del Almirante Doria. Fue el jefe de la expedición a Túnez y del asalto de la Goleta. Fue gobernador del Milanesado; tras ser derrotado en la batalla de Cerisola cayó en desgracia y se retiró a Lombardía; murió en Milán en 1546.

18 Francisco de Figueroa, Poesía, edición de Mercedes López Suárez, Madrid, Cátedra, 1989.

19 Oda XIV del Libro I de Horacio.

20 Francisco de Aldana, Poestas, edición de Ellas L. Rivers, Madrid, Espasa-Calpe, 1966.

21 Rodríguez Moñino creyó que Aldana nació en el pueblo extremefio de Alcántara. 
LOS POETAS-SOLDADOS Y EL TRASVASE CULTURAL EN EL RENACIMIENTO

22 Véase "Aldana en la crítica y la literatura" en C. Ruiz Silva, Estudios sobre Francisco de Aldana, Dpt. ${ }^{\circ}$ de Literatura Espafiola, Facultad de Filosoffa y Letras, Universidad de Valladolid, 1981.

23 Por ejemplo, Hurtado de Mendoza tradujo en Venecia la Mecanica, escribió Paraphrasis in totum Aristotelem y compuso una parte considerable de su obra poética al modo italiano. 